\title{
Book review:A heart for work; journeys through an African Medical school.
}

\section{Author: Claire .L.Wendland Reviewer:Robin.L. Broadhead}

Dr Claire. L .Wendland, the author of "A Heart For The Work: Journeys Through an African Medical School" is a physician and an anthropologist. She first visited Malawi in 1990 as a medical student. She returned in 2002-2003 to embark on a $\mathrm{PhD}$ study. Her aim was to chart the impact of medicine as practiced and taught in Malawi on the attitudes of medical student of the University of Malawi Medical School. "A Heart for the Work" is the fruit of her study. It describes the academic progress as journeys of medical students as they embark on their studies at the College of Medicine.

"A Heart For the Work: Journeys through an African Medical School " is a beautifully crafted book. As the title suggests the author traces a journey of medical students from their reception into the University of Malawi, College of Medicine, through their preclinical training into the corridors of the Queen Elizabeth Central hospital. She also later records the reflections of those students who have graduated and have practiced as intern doctors. The author does this against a historical background that is well researched and which sets the scene for the events that led to the creation of the College of Medicine.

What is remarkable about "A heart for the Work" is that Claire Wendland allows the voices of the students to speak for themselves. She traces the initial motives and idealism for students taking up the profession of Medicine in the first place. She goes on to record how students experience and adapt to their first two years of training in the basic medical science disciplines. But it is in chapter 5 'The Word made Flesh', that the raw experience of the next three years of clinical training really impacts on the lives of the students and their perceptions. Here the student voices ring with authentic bewilderment as they make the transition from medicine as disembodied medical knowledge to incarnational clinical practice.

In the chapter 'Resources as verb' Claire Wendland records through the stories of the students how as newly graduated doctors, they have adapted to the realities and constraints of actual clinical practice. What seems to emerge is that in general the training the students receive equips them for the medical practice they could anticipate as junior doctors. When Professor John Chiphangwi, the first Dean, pioneered the setting up of the Medical School, he and his colleagues resolved to create a medical curriculum that was directly related to Malawi's medical problems and needs. The curriculum was to be firmly based in community and public health. The College of Medicine in Malawi was emphatically not to be an ivory tower institution. Paradoxically the very astute and perceptive observations and criticisms voiced by the students themselves seem to endorse the original vision as set out in the mission statement of the College. The most important conclusion that emerges from "The Heart for the Work " is that the students that graduate from the College in general care and care greatly for their patients and their communities, as stated by the author "When the doctors -tobe talked about work, they used the word spirit (or love or heart) for the work interchangeably with spirit (or love or heart) for the people; the people were the Malawians and they were the work ."

Claire Wendland accompanies the students on their journeys with a lucid commentary. Her analysis is both critical and compassionate. The author's sharp eye for detail makes her descriptions lively and perceptive. Although the core of the work stems from a study for a doctoral thesis, the pace of the story never flags. Claire Wendland has, in the best tradition of medicine,demonstrated how the histories and stories remain the bedrock of medical writing and clinical practice. "A Heart for the Work" is a very good read and a valuable resource for those wishing to understand the process of medical training in a resource poor environment. It should be required reading for anyone involved in training medical students in any context and environment.

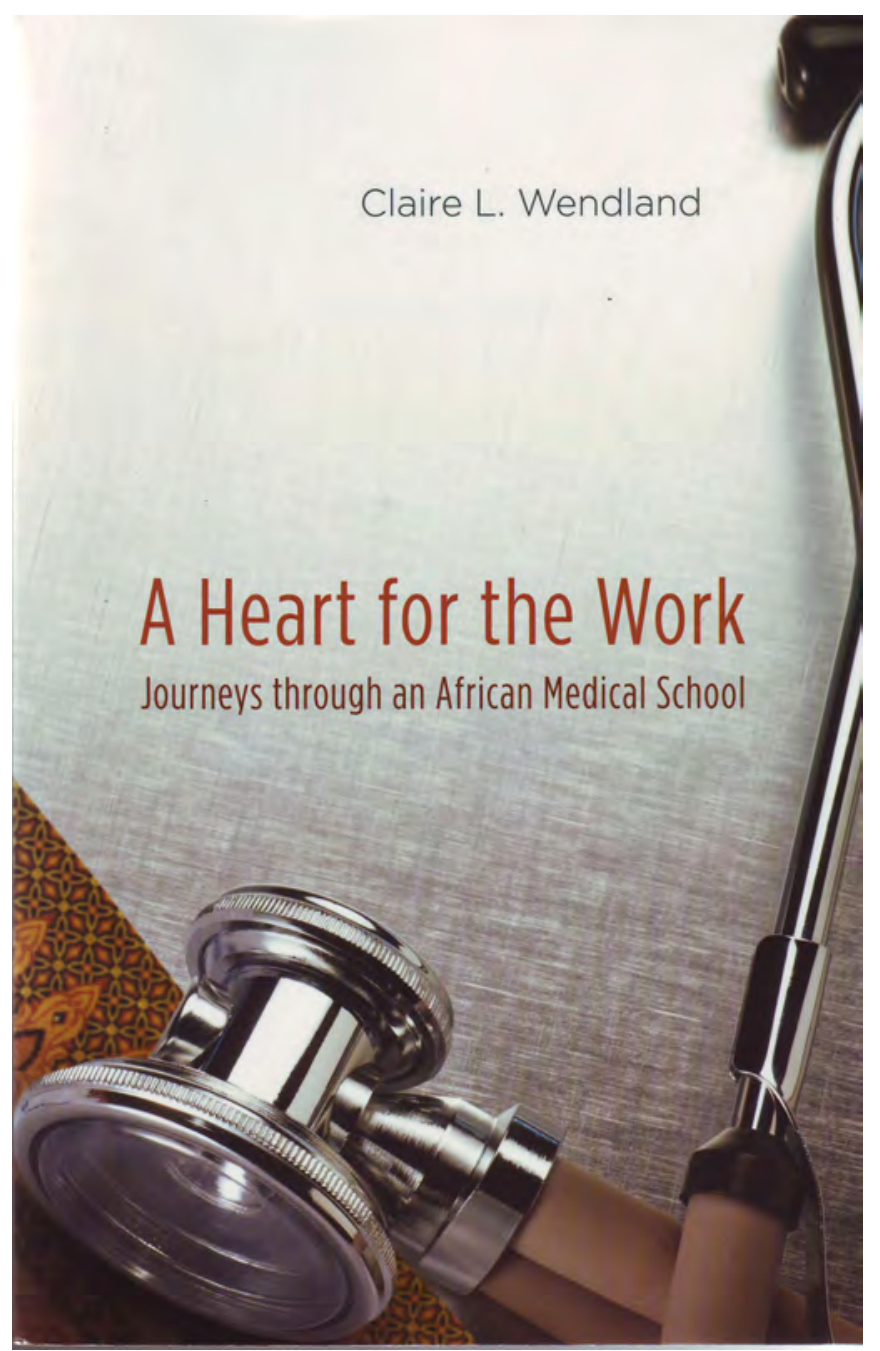

